\title{
Prevention of Over-Pressurization During Combustion in a Sealed Chamber
}

Suleyman A. Gokoglu, Justin E. Niehaus, Sandra L. Olson, Daniel L. Dietrich, and Gary A. Ruff Glenn Research Center, Cleveland, Ohio

Paul V. Ferkul and Michael C. Johnston

National Center for Space Exploration, Glenn Research Center, Cleveland, Ohio 


\section{NASA STI Program . . . in Profile}

Since its founding, NASA has been dedicated to the advancement of aeronautics and space science. The NASA Scientific and Technical Information (STI) program plays a key part in helping NASA maintain this important role.

The NASA STI Program operates under the auspices of the Agency Chief Information Officer. It collects, organizes, provides for archiving, and disseminates NASA's STI. The NASA STI program provides access to the NASA Aeronautics and Space Database and its public interface, the NASA Technical Reports Server, thus providing one of the largest collections of aeronautical and space science STI in the world. Results are published in both non-NASA channels and by NASA in the NASA STI Report Series, which includes the following report types:

- TECHNICAL PUBLICATION. Reports of completed research or a major significant phase of research that present the results of NASA programs and include extensive data or theoretical analysis. Includes compilations of significant scientific and technical data and information deemed to be of continuing reference value. NASA counterpart of peer-reviewed formal professional papers but has less stringent limitations on manuscript length and extent of graphic presentations.

- TECHNICAL MEMORANDUM. Scientific and technical findings that are preliminary or of specialized interest, e.g., quick release reports, working papers, and bibliographies that contain minimal annotation. Does not contain extensive analysis.

- CONTRACTOR REPORT. Scientific and technical findings by NASA-sponsored contractors and grantees.
- CONFERENCE PUBLICATION. Collected papers from scientific and technical conferences, symposia, seminars, or other meetings sponsored or cosponsored by NASA.

- SPECIAL PUBLICATION. Scientific, technical, or historical information from NASA programs, projects, and missions, often concerned with subjects having substantial public interest.

- TECHNICAL TRANSLATION. Englishlanguage translations of foreign scientific and technical material pertinent to NASA's mission.

Specialized services also include creating custom thesauri, building customized databases, organizing and publishing research results.

For more information about the NASA STI program, see the following:

- Access the NASA STI program home page at http://www.sti.nasa.gov

- E-mail your question to help@sti.nasa.gov

- Fax your question to the NASA STI Information Desk at 443-757-5803

- Phone the NASA STI Information Desk at 443-757-5802

- Write to: STI Information Desk NASA Center for AeroSpace Information 7115 Standard Drive Hanover, MD 21076-1320 
NASA/TM-2012-217712

AIAA-2012-3511

Prevention of Over-Pressurization During Combustion in a Sealed Chamber

Suleyman A. Gokoglu, Justin E. Niehaus, Sandra L. Olson, Daniel L. Dietrich, and Gary A. Ruff Glenn Research Center, Cleveland, Ohio

Paul V. Ferkul and Michael C. Johnston

National Center for Space Exploration, Glenn Research Center, Cleveland, Ohio

Prepared for the

42nd International Conference on Environmental Systems

sponsored by the American Institute of Aeronautics and Astronautics

San Diego, California, July 15-19, 2012

National Aeronautics and

Space Administration

Glenn Research Center

Cleveland, Ohio 44135 
Level of Review: This material has been technically reviewed by technical management.

Available from

NASA Center for Aerospace Information 7115 Standard Drive

Hanover, MD 21076-1320
National Technical Information Service 5301 Shawnee Road Alexandria, VA 22312

Available electronically at http://www.sti.nasa.gov 


\title{
Prevention of Over-Pressurization During Combustion in a Sealed Chamber
}

\author{
Suleyman A. Gokoglu, Justin E. Niehaus, Sandra L. Olson, Daniel L. Dietrich, and Gary A. Ruff \\ National Aeronautics and Space Administration \\ Glenn Research Center \\ Cleveland, Ohio 44135 \\ Paul V. Ferkul and Michael C. Johnston \\ National Center for Space Exploration \\ Glenn Research Center \\ Cleveland, Ohio 44135
}

\begin{abstract}
The combustion of flammable material in a sealed chamber invariably leads to an initial pressure rise in the volume. The pressure rise is due to the increase in the total number of gaseous moles (condensed fuel plus chamber oxygen combining to form gaseous carbon dioxide and water vapor) and, most importantly, the temperature rise of the gas in the chamber. Though the rise in temperature and pressure would reduce with time after flame extinguishment due to the absorption of heat by the walls and contents of the sealed spacecraft, the initial pressure rise from a fire, if large enough, could lead to a vehicle overpressure and the release of gas through the pressure relief valve. This paper presents a simple lumpedparameter model of the pressure rise in a sealed chamber resulting from the heat release during combustion. The transient model considers the increase in gaseous moles due to combustion, and heat transfer to the chamber walls by convection and radiation and to the fuel-sample holder by conduction, as a function of the burning rate of the material. The results of the model are compared to the pressure rise in an experimental chamber during flame spread tests as well as to the pressure fall-off after flame extinguishment. The experiments involve flame spread over thin solid fuel samples. Estimates of the heat release rate profiles for input to the model come from the assumed stoichiometric burning of the fuel along with the observed flame spread behavior. The sensitivity of the model to predict maximum chamber pressure is determined with respect to the uncertainties in input parameters. Model predictions are also presented for the pressure profile anticipated in the Fire Safety-1 experiment, a material flammability and fire safety experiment proposed for the European Space Agency (ESA) Automated Transfer Vehicle (ATV). Computations are done for a range of scenarios including various initial pressures and sample sizes. Based on these results, various mitigation approaches are suggested to prevent vehicle overpressurization and help guide the definition of the space experiment.
\end{abstract}

\section{Nomenclature}

$\mathrm{A}_{\mathrm{f}} \quad$ area of the flame over the fuel-sample surface, $\mathrm{m}^{2}$

$\mathrm{A}_{\mathrm{w}} \quad$ area of the total available surfaces heat is convected to, $\mathrm{m}^{2}$

$\mathrm{C}_{\mathrm{v}, \mathrm{g}} \quad$ molar specific heat of gas at constant volume, $\mathrm{J} / \mathrm{mol}-\mathrm{K}$

FP average fire power obtained from the integration of $\mathrm{q}_{\text {comb }}$ over $\tau, \mathrm{W}$

$\mathrm{L} \quad$ characteristic length for convection, $\mathrm{m}$

$\mathrm{Nu} \quad$ Nusselt number for heat transfer

$\mathrm{P}_{\mathrm{i}} \quad$ pressure, atm

Pr Prandtl number

Q thermal energy accumulation, $\mathrm{J}$

$\mathrm{Re}_{\mathrm{L}} \quad$ Reynolds number based on characteristic length $\mathrm{L}$

$\mathrm{T}_{\mathrm{f}} \quad$ average flame temperature, $\mathrm{K}$ 


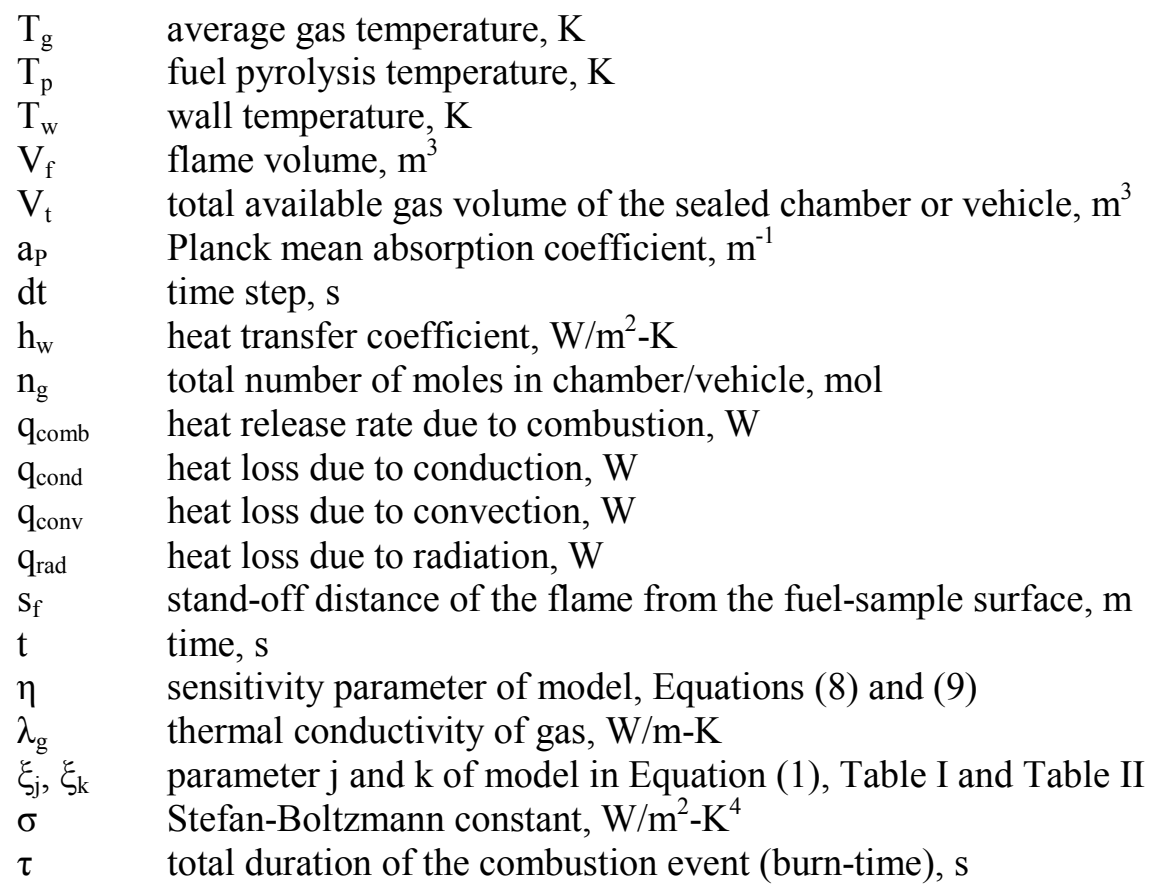

\section{Subscripts \\ max maximum \\ o baseline case}

\section{Introduction}

The objective of NASA's Advanced Exploration Systems Program is to advance and demonstrate technologies such that they can be implemented on future exploration systems. Because of the importance of fire safety technologies in spacecraft design, a project titled Spacecraft Fire Safety Demonstrations was recently initiated with the sole purpose of closing the technology gaps by conducting a fire safety experiment in an orbiting vehicle.

The work conducted to date has shown that fire behavior in low-gravity is very different from that in normal-gravity, with differences observed for flammability limits, spread rates, and flame structures (Ref. 1). As a result, the prediction of the behavior of fires in reduced gravity is at present not validated. The proposed fire safety experiment, titled Fire Safety-1, seeks to address this gap in the knowledge through the use of an unmanned but pressurized cargo transfer vehicle.

The current concept is to conduct this experiment in an ISS resupply vehicle such as the ATV, Cygnus, HTV, or Dragon, after it departs the ISS and before it experiences significant g-forces as it enters the atmosphere. While the requirements are still being developed, the current concept focuses on conducting two types of material flammability tests that would be performed sequentially and can proceed autonomously. The first set of tests would consist of up to nine samples of varying materials, each having dimensions of approximately $10 \mathrm{~cm}$ wide by $30 \mathrm{~cm}$ long. These samples emulate the configuration used in NASA Standard 6001 Test 1. There would be an external air flow from the bottom of the samples to the top and each sample would be ignited at the bottom using a hot wire. Minimal diagnostics would be required for these tests as the intended result is primarily to determine whether the flame propagates or self-extinguishes.

The second test will investigate flame spread over a panel of thin material approximately $0.5 \mathrm{~m}$ wide by $1.0 \mathrm{~m}$ long. As in the previous tests, the ignition method would be a hot wire along the upstream edge. This material will be expected to burn at the anticipated cabin atmosphere. The objective of this test is to quantify the flame development over a large sample in low-gravity. This sample will be more heavily 
instrumented with multi-view video, thermocouples, radiometers, etc. so that the data can be used to verify numerical simulations of fire spread and development in low-g.

To ensure safe reentry of the orbiting vehicle, the combustion event in the proposed Fire Safety-1 experiment must not raise the internal pressure of the vehicle above the allowed limits. The pressure rise from this experiment is most readily controlled by limiting the amount of fuel that is available to burn.

Given the low mass of air in the vehicle, if all of the energy from a fire went to heat the gas-phase, the pressure rise could be quite high. Much of the heat, however, is absorbed by surrounding objects where it causes an insignificant increase in their temperature. Consequently, accurate prediction of the pressure rise resulting from a combustion test requires good estimates of the fraction of the heat that is directly absorbed by the vehicle walls and physical objects contained in the vehicle. At this point in the development of the experiment, many of these parameters can only be estimated. The necessary thermal modeling to provide a robust prediction of the pressure transient caused by the flame is underway. In the meantime and while the experiment is being better defined, a more practical, but rational, approach has been taken to estimate and manage the pressure rise during the flame event.

In this paper, we describe this practical model, our approaches to validate it with limited groundbased, normal-gravity experiments, and our attempts to predict pressure profiles and maximum pressures anticipated in the Fire Safety-1 experiment assuming that the experiment will be conducted in the European Space Agency (ESA) Automated Transfer Vehicle (ATV). Various scenarios and mitigation approaches will be presented in order to prevent over-pressurization in the ATV vehicle.

\section{Model Description}

The model accounts for the energy gain and loss mechanisms that occur during the combustion process. A transient energy balance includes the energy gain due to the burning rate and the associated energy release rate for a typical fuel material $\left(\mathrm{q}_{\mathrm{comb}}\right)$ to be identified. The energy losses are due to heat transfer by radiation from the flame to the vehicle walls $\left(\mathrm{q}_{\mathrm{rad}}\right)$, by convection from the heated gases (which expand as well as get convected) to the vehicle walls $\left(\mathrm{q}_{\mathrm{conv}}\right)$, and by conduction from the flame to the fuel-sample holder $\left(\mathrm{q}_{\text {cond }}\right)$. The resulting expression for energy accumulation in the vehicle is

$$
\mathrm{d}(\mathrm{Q}) / \mathrm{dt}=\mathrm{q}_{\mathrm{comb}}-\mathrm{q}_{\mathrm{rad}}-\mathrm{q}_{\mathrm{conv}}-\mathrm{q}_{\mathrm{cond}}
$$

The transient term on the left-hand side can be written as

$$
\mathrm{d}(\mathrm{Q}) / \mathrm{dt}=\mathrm{C}_{\mathrm{v}, \mathrm{g}} \mathrm{d}\left(\mathrm{n}_{\mathrm{g}} \mathrm{T}_{\mathrm{g}}\right) / \mathrm{dt}
$$

where $\mathrm{C}_{\mathrm{v}, \mathrm{g}}$ is the molar specific heat of the gas (air) at constant volume, $\mathrm{n}_{\mathrm{g}}$ is the total number of gaseous moles in the chamber/vehicle and varies with time during combustion due to reaction stoichiometry, and $\mathrm{T}_{\mathrm{g}}$ is the gas temperature averaged over the chamber/vehicle volume.

For determining the energy gain during combustion, Huggett's recommended heat release factor of $13,100 \mathrm{~kJ} / \mathrm{kg}_{-} \mathrm{O}_{2}$ has been used (Ref. 2). The heat release rate $\mathrm{q}_{\mathrm{comb}}$ has been related to the burning rate of the fuel via this heat release factor. The basic chemical unit of the fuel has been assumed to be cellulose with a molecular formula of $\mathrm{C}_{6} \mathrm{H}_{10} \mathrm{O}_{5}$ and burning stoichiometrically; i.e., $\mathrm{C}_{6} \mathrm{H}_{10} \mathrm{O}_{5}+6 \mathrm{O}_{2} \rightarrow 6 \mathrm{CO}_{2}+5 \mathrm{H}_{2} \mathrm{O}$.

The time-dependent burning rate profile of the fuel in ground-based, normal-gravity experiments has been inferred from visual observations of flame behavior in recorded videos of the combustion event conducted in sealed chambers of various volumes filled with air. Typically, the flame grows to a steady size soon after the fuel is ignited and diminishes in a brief period to flame out. The observed flame behavior has been described as an approximate function of time for the duration of the burn, which in turn has been used to get an indirect estimate of the instantaneous burning rate, and hence, the instantaneous

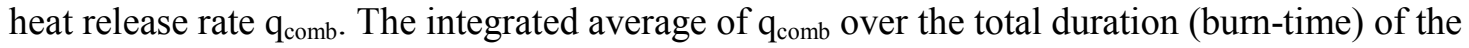
combustion event, $\tau$, is an important parameter which we call the fire power, FP. The $\mathrm{O}_{2}$ consumption, 
and $\mathrm{CO}_{2}$ and $\mathrm{H}_{2} \mathrm{O}$ generation rates have been calculated from the inferred fuel burning rate, the chemical composition of the fuel, and assuming a stoichiometric combustion process.

For predicting the pressure rise in the ATV under microgravity conditions, the energy release is estimated using the area density of a potential thin fuel and burning rate is estimated conservatively by using correlations developed for microgravity flame spread rates of a lower area density fuel (i.e., Kimwipe (Ref. 3).

The radiative heat loss to the walls of the chamber/vehicle can occur both by the solid particulate matter (smoke and soot) generated during combustion and gas-phase radiation, primarily from $\mathrm{CO}_{2}$ and $\mathrm{H}_{2} \mathrm{O}$. The current calculations neglect particulate radiation (usually the larger fraction), and hence are more conservative. The radiative loss term is expressed as

$$
\mathrm{q}_{\mathrm{rad}}=\mathrm{a}_{\mathrm{P}} \mathrm{V}_{\mathrm{f}} \sigma\left(\mathrm{T}_{\mathrm{f}}^{4}-\mathrm{T}_{\mathrm{w}}{ }^{4}\right)
$$

where $a_{P}$ is the Planck mean absorption coefficient, $V_{f}$ is the radiating flame volume, $\sigma$ is the StefanBoltzmann constant, $T_{f}$ is the flame temperature averaged over flame volume, and $T_{w}$ is the temperature of the wall the flame is radiating to.

The convective heat loss term is expressed as

$$
\mathrm{q}_{\text {conv }}=\mathrm{h}_{\mathrm{w}} \mathrm{A}_{\mathrm{w}}\left(\mathrm{T}_{\mathrm{g}}-\mathrm{T}_{\mathrm{w}}\right)
$$

where $h_{w}$ is the convective heat transfer coefficient between the heated gas and walls of the chamber/vehicle, and $\mathrm{A}_{\mathrm{w}}$ is the total surface area of the walls available for convective heat transfer. The heated gas carried downstream by buoyant convection in normal gravity or by forced convection in the planned space flight experiments is expected to circulate inside the chamber/vehicle, so we assume that for our purposes, a flow-over-a-flat-plate type of correlation would be sufficient to approximate the convective heat transfer coefficient. Therefore, we use the following average Nusselt number correlation

$$
\mathrm{Nu}_{\mathrm{L}}=\mathrm{h}_{\mathrm{w}} \mathrm{L} / \lambda_{\mathrm{g}}=0.664 \operatorname{Pr}^{1 / 3} \operatorname{Re}_{\mathrm{L}}^{1 / 2}
$$

where $\mathrm{L}$, the distance from the leading edge of the flat plate, is conveniently taken in this analysis as the known diameter (i.e., the characteristic length) of the chamber/vehicle, $\lambda_{\mathrm{g}}$ is the thermal conductivity of the gas (air), Pr is the Prandtl number of the gas (air), and $\mathrm{Re}_{\mathrm{L}}$ is the Reynolds number based on the characteristic length $\mathrm{L}$. The properties of the gas have been evaluated at an average temperature and pressure during the combustion event and usually taken as their initial values prior to combustion unless their variations are non-negligible. The Reynolds number is a function of the expected gas velocities which have either been estimated from buoyant convection in ground-based, normal-gravity experiments or from anticipated operational speeds of the fans to be used in the space flight experiment $(\sim 15 \mathrm{~cm} / \mathrm{s})$.

The estimates for conductive heat losses have been guided by ground-based experiments conducted at NASA Glenn Research Center using various candidate fuel materials for the flight experiment. For some of these experiments, the fuel sample and the fuel-sample holder configuration do not warrant a consideration of conductive losses. However, when a specific fuel-sample material developed in-house is burned then the $\mathrm{q}_{\mathrm{cond}}$ term is non-negligible and needs to be accounted for. In this case, the fuel sample is woven into a non-burning, flexible matrix material for ease of handling and mounted on both sides to high-conductivity metallic strips. The conductive heat loss term is then expressed as

$$
\mathrm{q}_{\text {cond }}=\lambda_{\mathrm{g}}\left(\mathrm{T}_{\mathrm{f}}-\mathrm{T}_{\mathrm{p}}\right)\left(\mathrm{A}_{\mathrm{f}} / \mathrm{s}_{\mathrm{f}}\right)
$$

where $\lambda_{\mathrm{g}}$ is the thermal conductivity of the gas (air) evaluated at an average temperature between $\mathrm{T}_{\mathrm{f}}$ and $T_{p}, T_{p}$ is the pyrolysis temperature of the cellulosic fuel $(\sim 900 \mathrm{~K}), A_{f}$ is the area of the flame over the fuel sample, and $\mathrm{s}_{\mathrm{f}}$ the flame stand-off distance from the fuel sample. The video images of the ground-based experiments help determine the approximate length of the propagating flame over the fuel sample and, knowing the fuel sample width, allows us to estimate the flame area $A_{\mathrm{f}}$. In the absence of side-view 
images of propagating flames, the flame stand-off distance has also been estimated to be in the order millimeters.

There is also no straightforward way to estimate $\mathrm{T}_{\mathrm{f}}$ for the purposes of the practical model outlined here. Whenever it is necessary to account for conductive heat loss $\mathrm{q}_{\text {cond }}$ then a flame temperature estimate of $1800 \mathrm{~K}$ is used in Equation (6).

Similar to the approximations involved in estimating $T_{\mathrm{f}}$, estimating the flame volume $\mathrm{V}_{\mathrm{f}}$ is just as challenging. An approach would be to estimate $V_{\mathrm{f}}$ from the assumed flame size which in turn is related to the $\mathrm{q}_{\text {comb. }}$. The smaller flame volume would result in higher average species concentrations despite a higher flame temperature. However, this introduces another unknown variable into the formulation which for this analysis has been deemed unnecessary. Therefore, the more readily accessible quantities have been substituted in Equation (3). The radiating volume $V_{\mathrm{f}}$ is assumed to be the sealed volume of the chamber/vehicle $\mathrm{V}_{\mathrm{t}}$. The Planck mean absorption coefficient $\mathrm{a}_{\mathrm{p}}$ for the gas in the chamber/vehicle is computed using the volume-average mole fractions for $\mathrm{CO}_{2}$ and $\mathrm{H}_{2} \mathrm{O}$ vapor (Ref. 4) in $\mathrm{V}_{\mathrm{t}}$ at the volumeaverage mean gas temperature $\mathrm{T}_{\mathrm{g}}$. As such, the radiative loss term has been approximated as

$$
\mathrm{q}_{\mathrm{rad}} \approx \mathrm{a}_{\mathrm{P}} \mathrm{V}_{\mathrm{t}} \sigma\left(\mathrm{T}_{\mathrm{g}}^{4}-\mathrm{T}_{\mathrm{w}}{ }^{4}\right)
$$

Using the above definitions of each term in Equation (1), the energy balance equation can be integrated and the average gas temperature rise can be calculated as a function of time. The corresponding instantaneous pressure rise has been calculated using the ideal gas law for the constant volume of the chamber/vehicle.

\section{Model Calibration and Validation}

The transient lumped-parameter model described above has a number of variables which require estimations for making predictions. One way to avoid some of the uncertainties in the estimations is to anchor the model prediction to an experimental result by tuning the values of the model variables until a reasonably good fit between the model and experiment is obtained.

The approach has been to utilize the pressure versus time profile measured in a sealed cylindrical chamber of $\sim 37$ liters by burning Whatman 44 ashless filter paper of dimensions $5 \mathrm{~cm}$ by $18 \mathrm{~cm}$. Igniter is located at the bottom for upward flame propagation, i.e., concurrent with buoyant convection but with no forced convection. Some of these experiments used a thin holder on the sides of the paper while one case was without a holder, basically holding the paper from one of its corners hanging in the chamber. Since there was nothing else inside the chamber and the experimental results indicate that the presence of the holder practically has no effect on the measured pressure-time trace except towards the end and after flameoff, the conductive loss term expressed by Equation (6) can be confidently eliminated from the model. For the amount of fuel burned, the total amount of energy released is calculated to be about $10.75 \mathrm{~kJ}$. Even then, there are a number of variables that can be adjusted in the model to match the predictions to the experiment, so the calibration of the model does not give a unique answer for the best fit.

Figure 1 shows the experimental curves and the best fit of model predictions based on our visual, qualitative judgment. This fit is obtained by (a) taking the total burn-time as $8 \mathrm{~s}$ (the experiment reports an estimated burn-time less than $10 \mathrm{~s}$ ), (b) applying a heat release rate versus time profile such that the power rises linearly to its maximum level of $2.38 \mathrm{~kW}$ in $3 \mathrm{~s}(37.5$ percent of total burn-time), stays at the maximum level for $1 \mathrm{~s}$ (12.5 percent of total burn-time), and decays linearly to flame-off in $4 \mathrm{~s}$ (50 percent of total burn-time), and (c) using a convective heat transfer coefficient, $h_{w}$, of $44 \mathrm{~W} / \mathrm{m}^{2}-\mathrm{K}$. Note that the applied heat release rate profile satisfies the total energy release of $10.75 \mathrm{~kJ}$ calculated for this amount of fuel. If the chamber walls were adiabatic the calculated maximum pressure for this experiment would be 31.5 psia, indicating that about 74 percent of the total energy is lost to the environment.

Figure 2 shows a similar fit to the experimental curves by another possible combination of model parameters. This time, the heat release rate profile follows a path rising linearly to its maximum level of $2.15 \mathrm{~kW}$ in 25 percent of burn-time $(2 \mathrm{~s})$, staying at the maximum level for 25 percent of burn-time $(2 \mathrm{~s})$, 


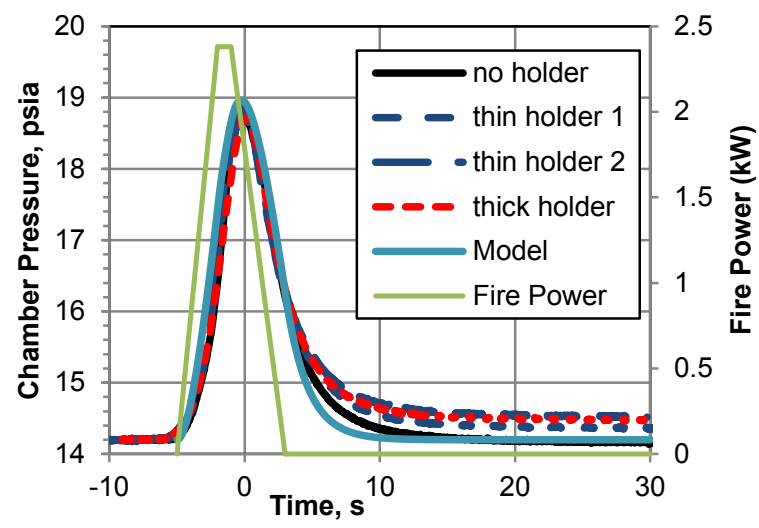

Figure 1.-Experimental pressure profiles and our best matching prediction by calibrating model parameters; Whatman 44 ashless filter paper, $5-$ by $18-\mathrm{cm}$.

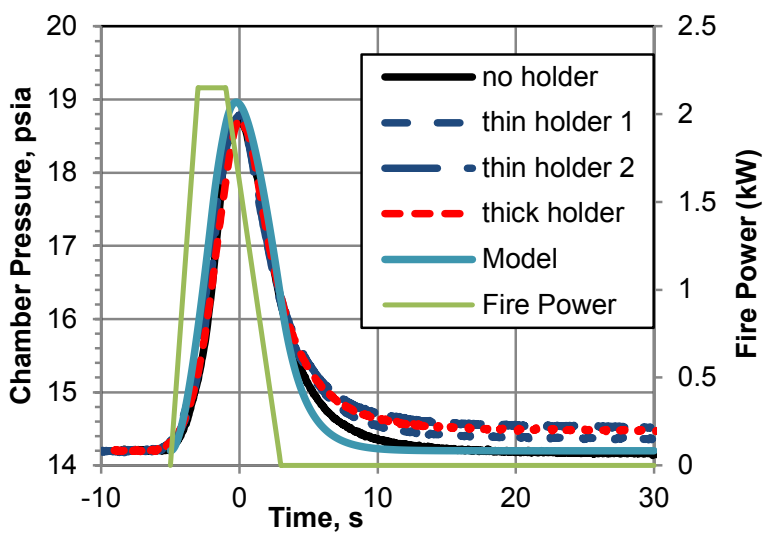

Figure 2.-Experimental pressure profiles and another close fit by a different calibration of model parameters; Whatman 44 ashless filter paper, $5-$ by $18-\mathrm{cm}$.

and decaying linearly to flame-off in 50 percent of burn-time $(4 \mathrm{~s})$, but also satisfying the total released energy constraint of $10.75 \mathrm{~kJ}$. Matching the maximum peak pressure is accomplished by using a $\mathrm{h}_{\mathrm{w}}$ value of $42 \mathrm{~W} / \mathrm{m}^{2}-\mathrm{K}$. Though this calibration can also be viewed as acceptable, it has a faster initial rise and underpredicts the later stages of pressure decay. Given the model assumptions employed for describing the process, a more rigorous quantitative measure of judging the goodness of the fits is deemed to be unwarranted. We have therefore settled on the first set of model parameters resulting in the pressure trace depicted in Figure 1 for our calibration of the model.

Next, the calibrated model is used to predict transient pressure profiles measured in the same chamber but for different types and quantities (masses) of fuel of the same size; i.e., 5- by 10-cm. Even though the fuel material is bleached cheesecloth for all cases and it can be described as a cellulosic fuel with a basic molecular unit of $\mathrm{C}_{6} \mathrm{H}_{10} \mathrm{O}_{5}$, the experiments have employed types of cheesecloth materials with different area densities or burned different number of pieces stacked on top of each other with no glue or binding material in-between. The measured pressure traces of all of these various cases are depicted in Figure 3. The first two cases burn single pieces of cheesecloth of the same dimensions but of different mass due to differences in their area density while the third case in the legend uses two pieces in a stack. It is experimentally observed that the thicker the fuel stack is the more incomplete and sooty the burn is. Also, as fuel stack gets thicker the final pressure at the end of the experiment starts to fall lower than the initial starting pressure. This may be due to the formation of condensable hydrocarbons from incomplete and $\mathrm{O}_{2}$-lean combustion of the fuel when stacked, although the amount of leftover $\mathrm{O}_{2}$ after burning the thickest stack (i.e., four pieces with a total of $856 \mathrm{mg}$ of fuel) is calculated to be not less than 18.5 percent; i.e., not vitiated relative to the flammability limit of $\sim 11.5$ percent. Note that while the measured peak pressure values of the thinner stacks increase with the amount of burnt fuel mass the values of the thicker stacks with three or four pieces do not consistently increase with the total energy released, even though all samples have the same length. Also notice that the positions of the reported spread and total burn times relative to the observed peak pressure position is not always the same, neither are they apart from one another in a consistent manner.

The top three cases in the figure legend display a long-time pressure behavior similar to the calibration cases in that final pressures settle at a level close to the initial pressures. The last two cases use three and four pieces of stacked 90 grade bleached cheesecloth and their final pressures fall significantly below their initial pressures, though both seem to interestingly settle at the same long-term value. We have picked only the two single-piece cases plus one case which is only double-stacked as an acceptable borderline situation (i.e., the top three cases in the figure legend) for comparison with our predictions. 
Figure 4 compares the model prediction against the second experimental case where a single piece of 90 grade bleached cheesecloth is burned. This material has a total mass of $214 \mathrm{mg}$ with total energy release of $3.32 \mathrm{~kJ}$. The experimentally reported spread time is $4 \mathrm{~s}$. The model does an excellent job of predicting both the peak pressure value and the full pressure profile. The final long-term pressure predicted by the model comes down to the initial level while the experimental curve remains slightly higher. If the chamber walls were adiabatic the calculated maximum pressure for this experiment would be 19.7 psia, indicating about 63 percent heat loss to the environment.

Figure 5 compares the model prediction against the third experimental case where two stacked pieces of 90 grade bleached cheesecloth are burned. This time, the fuel has a total mass of $428 \mathrm{mg}$ and the total energy release is $6.64 \mathrm{~kJ}$. For the reported spread time of $10 \mathrm{~s}$, the experimentally observed pressure peak

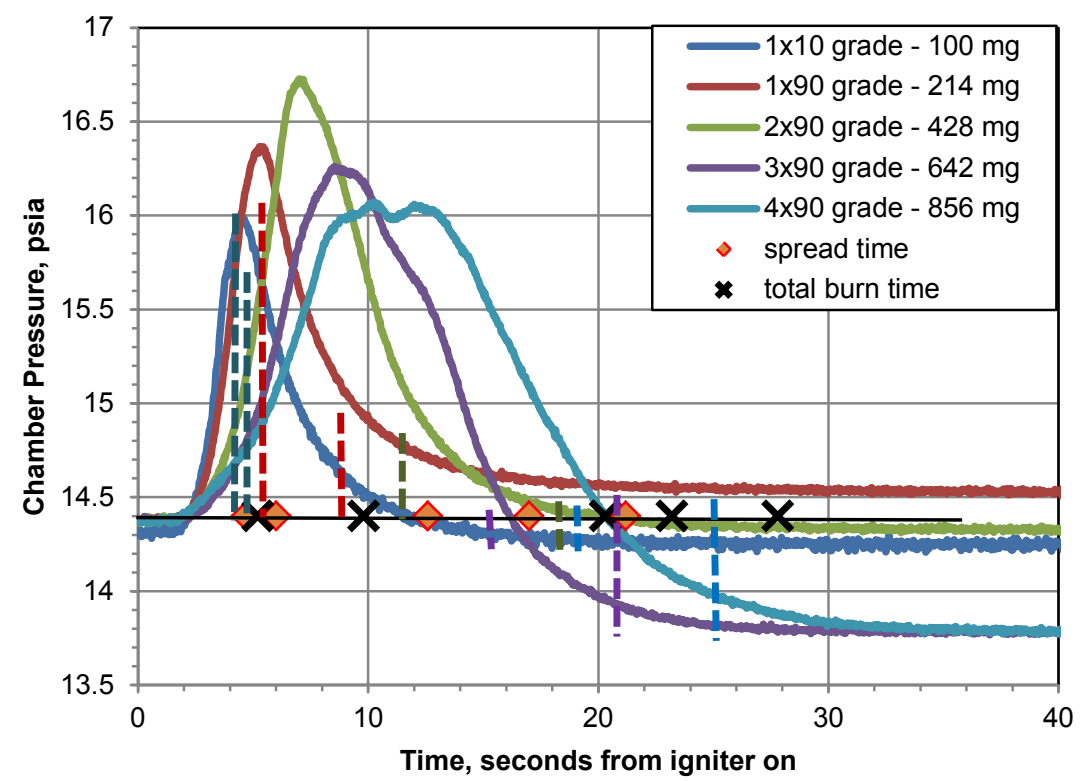

Figure 3.-Experimental pressure profiles for various types and quantities of fuel; bleached cheesecloth, 5- by10-cm.

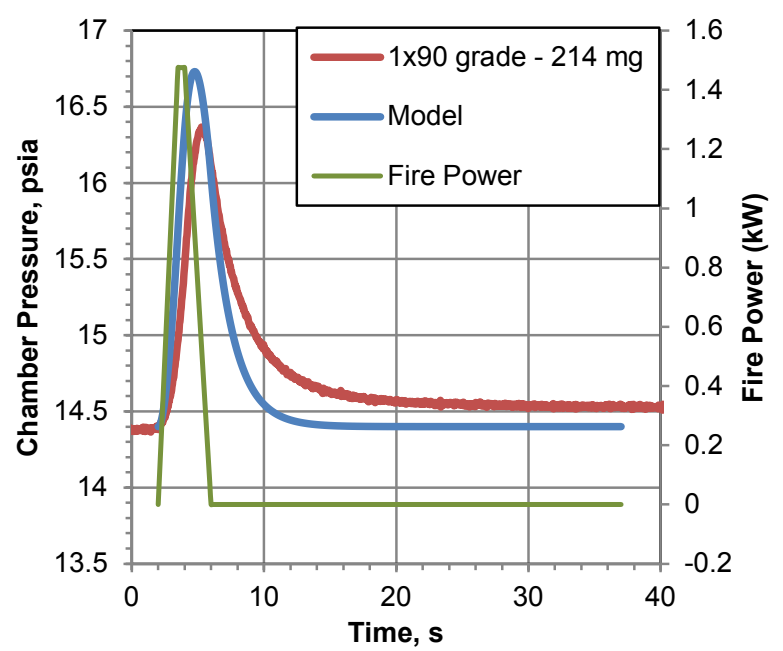

Figure 4.-Comparison of experimental pressure profile and calibrated model prediction; bleached cheesecloth, 5- by $10-\mathrm{cm}$.

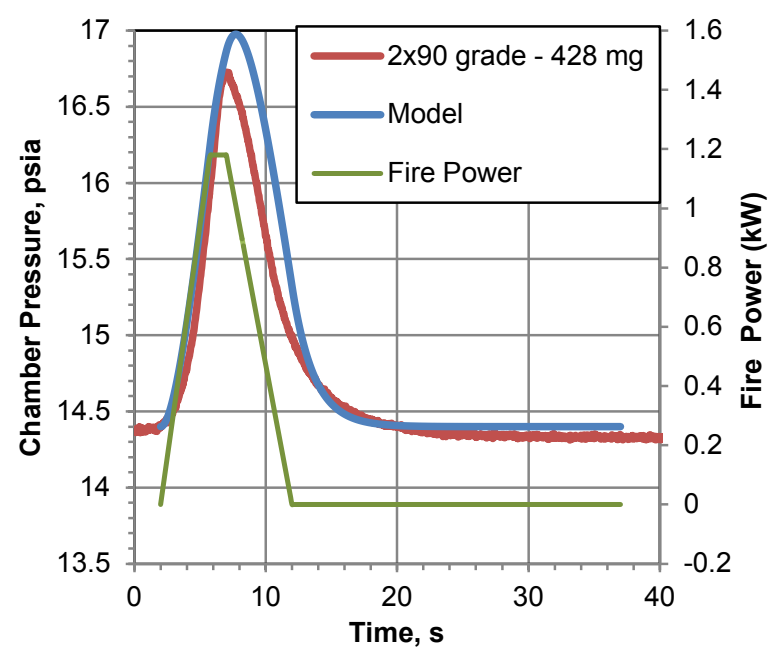

Figure 5.-Comparison of experimental pressure profile and calibrated model prediction; bleached cheesecloth, 5- by $10-\mathrm{cm}$. 


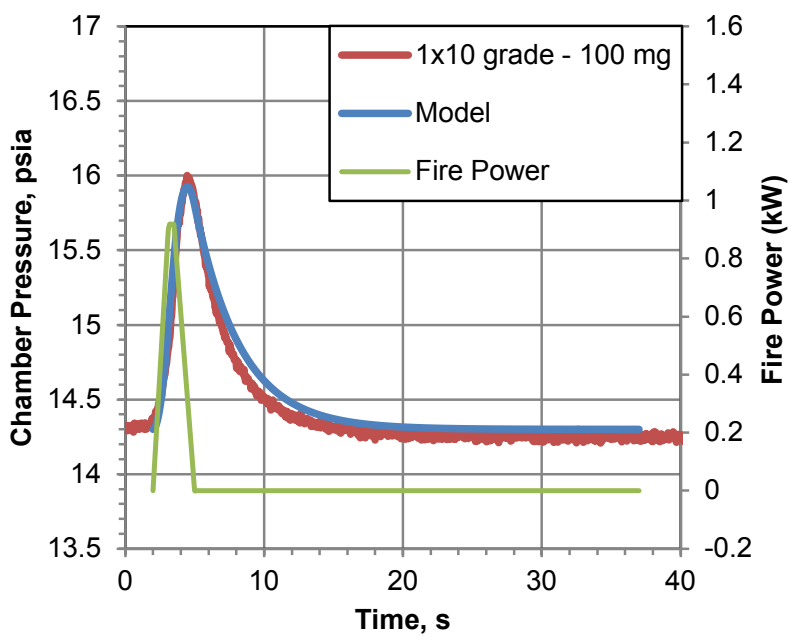

Figure 6.-Comparison of experimental pressure profile and calibrated model prediction; bleached cheesecloth, 5 - by $10-\mathrm{cm} ; \mathrm{h}_{\mathrm{w}}=22 \mathrm{~W} / \mathrm{m}^{2}-\mathrm{K}$ for heat loss.

is slightly higher than the two previous experimental cases. Again, the model does a very good job of predicting both the peak and the full profile of the experimental pressure curve. The final long-term values of both experimental and predicted pressures return to the initial starting level. For this case, adiabatic combustion would result at a maximum pressure of 25.0 psia, indicating about 79 percent heat loss to the environment.

Figure 6 depicts the first experimental case where a single piece of 10 grade bleached cheesecloth is burned. This material has a lower area density with a total mass of $100 \mathrm{mg}$ for the same fuel sample size. It burns relatively quickly reported to last for about $3 \mathrm{~s}$. The total energy release is only $1.55 \mathrm{~kJ}$, and the experimentally observed pressure peak is lower than the other measurements in the same series. If the same heat release rate profile obtained from the calibration and the same convective heat transfer coefficient of $44 \mathrm{~W} / \mathrm{m}^{2}-\mathrm{K}$ best describing the calibration cases were used also for this case then the model tends to overpredict the peak pressure value observed in the experiment. It is speculated that this discrepancy is mostly due to the fact that this light material which burns in a flash does not create sufficient gas expansion and buoyant convective motion in the chamber to generate as much heat loss as the other cases. In fact, when the model is run with the same heat release rate profile but with a smaller convective heat transfer coefficient of $22 \mathrm{~W} / \mathrm{m}^{2}-\mathrm{K}$ to reflect the smaller heat losses then the model captures the experimental pressure profile very accurately and predicts the peak value perfectly. Both the experimental and predicted final long-term pressure values come down to the initial level. The maximum pressure for adiabatic combustion in this case would be 16.9 psia, indicating a smaller heat loss of about 36 percent to the environment

Given the issues discussed about the experiments above, it seems that that the model can predict the pressure curves reasonably well covering a range of released total energies of 1.55 to $10.75 \mathrm{~kJ}$. The next challenge would be to check the model for predictions of pressure profiles both in a different enclosure of much larger volume so that the heat losses would be different and for sizes, masses, and types of fuels so that the energy contents and heat release rates would be different. Experiments in such an environment are currently underway using one of our in-house sealed facility chambers, namely VF-13. This chamber has basically a cylindrical shape with a diameter of $\sim 1.5 \mathrm{~m}$ and a height of $3.6 \mathrm{~m}$, resulting in an approximate total internal surface area of $18.73 \mathrm{~m}^{2}$ and volume of $6.35 \mathrm{~m}^{3}$. As such, VF-13 is more than two orders of magnitude larger than the 37-liter chamber we use here to calibrate our model. Our intention is to validate the performance of our model against the experiments conducted in VF-13, and improve it if necessary, as soon as the data becomes available. 


\section{Sensitivity Analysis of Model Predictions}

Given the level of estimations involved in determining the parameters of the model, it's important to understand the sensitivity of model predictions with respect to uncertainties in employed parameter values. Such an analysis would guide us in focusing our attention to the accuracy of the most critical ones among these parameters for the purpose of more reliably predicting the transient pressure profile as well as the maximum pressure in the enclosure. Moreover, it would also give indications on which parameters are most effective for preventing over-pressurization.

The solution of Equation (1) enables the prediction of transient temperature profiles, and via the use of the ideal gas law, the instantaneous pressure in an enclosure. We define a sensitivity parameter, $\eta$, based on the logarithmic change in the predicted maximum pressure relative to a logarithmic change in a given model parameter, $\xi_{\mathrm{j}}$, when all other parameters, $\xi_{\mathrm{k}}$, are held constant, i.e.,

$$
\eta=\left[\partial\left(\ln P_{\max }\right) / \partial\left(\ln \xi_{\mathrm{j}}\right)\right]_{\xi \mathrm{k}=\mathrm{constant}}
$$

Equation (8) can be approximated as

$$
\eta \approx\left(\xi_{\mathrm{i}} / \mathrm{P}_{\max }\right)_{\mathrm{o}}\left[\left(\Delta \mathrm{P}_{\max }\right) /\left(\Delta \xi_{\mathrm{j}}\right)\right]_{\xi \mathrm{k}=\mathrm{constant}}
$$

where the subscript "o" refers to the values for the baseline case. Logarithmic change allows normalizing the corresponding change in pressure with respect to a change in a given parameter such that each resulting sensitivity value can be compared to another on an equal and non-dimensional basis. We have varied the values of various, and mostly estimated, relevant parameters of the model by about \pm 5 percent of their baseline values (i.e., $\Delta \xi_{\mathrm{j}}= \pm 5$ percent $\xi_{\mathrm{j}}$ ) to calculate the corresponding changes of predicted maximum pressures. We have also tried changes in the range from \pm 2.5 to \pm 25 percent ascertaining the nearly linear behavior of the corresponding changes. Also note that some of these parameters may be interrelated; for example, a given characteristic length of the enclosure may define the surface area and volume of the enclosure. However, the sensitivity analysis ignores the interrelationships of parameters such that when one parameter is varied all other parameters are kept constant at their baseline values.

A baseline case is chosen from a typical experiment to be conducted in VF-13. We assume burning a fuel with a constant heat release rate of $10 \mathrm{~kW}$ and a total burn-time of about 60 s, i.e., a total energy release of $600 \mathrm{~kJ}$ and an average fire power, FP, of $10 \mathrm{~kW}$. To give a feel of what these values mean, note that burning about 8 sheets of regular paper (8.5- by 11 -in.) in a minute would have an equivalent energy release and fire power. We take the initial temperature as $293 \mathrm{~K}$ and pressure as $0.95 \mathrm{~atm}(963 \mathrm{hPa})$. For the calculation of convective heat loss rates, we assume a velocity of $15 \mathrm{~cm} / \mathrm{s}$ and a characteristic length of $1.5 \mathrm{~m}$, i.e., the diameter of VF-13.

Initially, we have neglected the conductive heat loss and implemented Equation (7) for the integration of Equation (1) and predicting the pressure profile. This baseline case gives a maximum pressure of $1.22 \mathrm{~atm}(1234 \mathrm{hPa})$ and maximum temperature of $376 \mathrm{~K}$. It should be mentioned that the corresponding maximum pressure and temperature if this process were adiabatic would be $1.33 \mathrm{~atm}(1346 \mathrm{hPa})$ and $408 \mathrm{~K}$. The calculations indicate that about 70 percent of the total energy has been gained by the gas in the enclosure and 30 percent has been lost to surroundings. The total contributions of individual heat loss terms for this specific situation, obtained by integrating instantaneous heat loss by convection and radiation over the burn-time, are 76 percent by convection and 24 percent by radiation. Table I provides the model sensitivity parameter, $\eta$, with respect to each of the model variable. The model sensitivity for predicting maximum pressure is highest, by definition, to the initial pressure, $\mathrm{P}_{\mathrm{i}}$. It is also understandable that the next most sensitive parameters are average fire power (FP), total internal volume of the enclosure $\left(\mathrm{V}_{\mathrm{t}}\right)$, and burn-time $(\tau)$ since they directly relate to the total amount of energy input to the enclosure as well as to heat release per unit volume and time. Sensitivities with respect to the parameters related to the heat losses from the system $\left(\mathrm{A}_{\mathrm{w}}, \mathrm{U}\right.$, and $\left.\mathrm{L}\right)$ are smaller relative to those parameters related to heat input to the system. 
TABLE I.-MODEL SENSITIVITY (ONLY CONVECTIVE AND RADIATIVE HEAT LOSSES)

Parameter, $\xi_{\mathrm{i}}$

\begin{tabular}{|c|c|c|c|c|c|c|c|c|}
\hline \multicolumn{7}{|c|}{ Radiation by Equation (7) } & \multicolumn{3}{c|}{ Radiation by Equation (3) } \\
\hline $\mathrm{P}_{\mathrm{i}}$ & $\mathrm{FP}$ & $\tau$ & $\mathrm{V}_{\mathrm{t}}$ & $\mathrm{A}_{\mathrm{w}}$ & $\mathrm{U}$ & $\mathrm{L}$ & $\mathrm{T}_{\mathrm{f}}$ & $\mathrm{V}_{\mathrm{f}}$ \\
\hline 0.86 & 0.21 & 0.14 & -0.15 & -0.05 & -0.03 & 0.03 & -0.05 & -0.01 \\
\hline
\end{tabular}

We have then explored the effect of substituting Equation (3) for Equation (7) for the treatment of the radiative loss term in Equation (1). For a fair comparison of these two different treatments the total contribution of radiative loss is kept the same such that the resulting maximum pressure from either treatment still gives the same value of $1.22 \mathrm{~atm}$. This constraint as well as the chosen baseline $T_{\mathrm{f}}$ value of $1800 \mathrm{~K}$ defines the baseline value for $\mathrm{V}_{\mathrm{f}}$. The last two columns of Table I provide the sensitivity values with respect to both $T_{f}$ and $V_{f}$. It is not surprising that radiative heat loss which depends on the fourth power of the flame temperature is more sensitive to $T_{f}$ than on $V_{f}$. Based on the sensitivities tabulated in Table I, the accurate determination of $\mathrm{T}_{\mathrm{f}}$ and the management of total internal surface area available for convective heat transfer are key variables for a more reliable prevention of over-pressurization in the enclosure.

Finally, we include the effect of conductive heat loss in the model in order to account for situations where, for example, the woven structure of the fuel into a non-burning matrix material and/or the fuel holder warrants the consideration of a conductive heat loss mechanism. From visual observations of burning an experimental thin fuel of dimensions 5 - by $180-\mathrm{cm}$ with equivalent energy release and fire power as before, we estimate the length of the flame $\left(\mathrm{L}_{\mathrm{f}}\right)$ propagating upward over the fuel to be about $20 \mathrm{~cm}$ and take the flame stand-off distance $\left(\mathrm{s}_{\mathrm{f}}\right)$ to be $1 \mathrm{~mm}$ for our baseline calculation. Here, the determination of flame characteristics (i.e., $\mathrm{V}_{\mathrm{f}}, \mathrm{L}_{\mathrm{f}}$, $\mathrm{s}_{\mathrm{f}}$, etc.) are based on direct visual examinations of flame video images and not correlated, for example, with heat of combustion or flame power. The flame temperature $\left(\mathrm{T}_{\mathrm{f}}\right)$ is assumed again to be $1800 \mathrm{~K}$. This baseline case, with the simpler treatment of the radiative term by using Equation (7), gives a maximum pressure of $1.20 \mathrm{~atm}(1213 \mathrm{hPa})$ and maximum temperature of $369 \mathrm{~K}$, both expectedly lower than the aforementioned case where only the convective and radiative heat losses are considered. For this case, the calculations indicate that about 65 percent of the total energy has been gained by the gas in the enclosure and 35 percent has been lost to surroundings. The total contributions of individual heat loss terms for this specific situation, obtained by integrating instantaneous heat loss by convection and radiation over the burn-time, are 59 percent by convection, 18 percent by radiation and 23 percent by conduction. The resulting sensitivity values are tabulated in Table II.

TABLE II.-MODEL SENSITIVITY (ALL HEAT LOSSES ACTIVE)

\begin{tabular}{|c|c|c|c|c|c|c|c|c|c|}
\hline \multicolumn{10}{|c|}{ Parameter, $\xi_{\mathrm{j}}$} \\
\hline \multicolumn{10}{|c|}{ Radiation by Equation (7) } \\
\hline $\mathrm{P}_{\mathrm{i}}$ & $\mathrm{FP}$ & $\tau$ & $\mathrm{V}_{\mathrm{t}}$ & $\mathrm{A}_{\mathrm{w}}$ & $\mathrm{U}$ & $\mathrm{L}$ & $\mathrm{T}_{\mathrm{f}}$ & $\mathrm{L}_{\mathrm{f}}$ & $\mathrm{s}_{\mathrm{f}}$ \\
\hline 0.87 & 0.21 & 0.14 & -0.14 & -0.05 & -0.03 & 0.03 & -0.03 & -0.02 & 0.02 \\
\hline
\end{tabular}

The model sensitivity is highest again to the initial pressure, followed by average fire power, enclosure gas volume, and burn-time. Convective heat transfer is the most important heat loss mechanism. It is noteworthy that while incorporation of conductive losses helps bring the maximum pressure down, the reported sensitivities of $\mathrm{T}_{\mathrm{f}}, \mathrm{L}_{\mathrm{f}}$, and $\mathrm{s}_{\mathrm{f}}$ are small relative to other parameters for worrying about their accuracy in our estimations. Conductive losses would play an insignificant role for drawing prudent conclusions from this analysis for preventing over-pressurization. Similarly, radiative loss is also secondary relative to convective loss. Among the convective loss parameters, the sensitivity is greatest to the available internal surface area $\left(\mathrm{A}_{\mathrm{w}}\right)$. Therefore, for a given energy input and heat release 
rate, it is recommended that attention is focused more on maximizing the area of convective heat transfer surfaces inside the enclosure for preventing its over-pressurization.

\section{Projections for Fire Safety-1 Experiment in ATV}

Despite its limited capabilities and insufficient validation, and until a more detailed and multidimensional thermal model is developed, the current model can still be used as a practical tool to guide us in designing the Fire Safety-1 experiment to be conducted on an orbiting vehicle such as the ATV.

We use our model for first-cut predictions of the transient pressure profiles and maximum pressures attainable in the ATV based on some preliminary definition of the Fire Safety-1 experiment. For the ATV vehicle constraints given in References 5 to 7, some mitigation approaches are suggested for safely conducting the experiment.

The contingency pressure limit of the ATV is given as $1048 \mathrm{hPa}$, but it is recommended that the engineering limit of $1035 \mathrm{hPa}$ not be exceeded. The Fire Safety-1 experiment currently plans to run flammability tests for nine small thin-fuel samples of dimensions $10-$ by $30-\mathrm{cm}$ and one large thin-fuel sample of dimension 50 - by $100-\mathrm{cm}$. Instead of considering the most conservative but unlikely possibility of burning all fuel samples simultaneously, we consider here the more realistic scenario of burning the large sample alone, given that small samples would result in smaller pressure rises. The resulting data obtained from our model is summarized in Table III for four possible conditions.

TABLE III.--RESULTS OF PRELIMINARY PRESSURE RISE CALCULATIONS FOR FIRE SAFETY-1-LARGE SAMPLE ONLY

\begin{tabular}{|c|c|c|c|c|c|c|c|c|c|c|}
\hline \multirow[t]{2}{*}{ Condition } & \multicolumn{2}{|c|}{ Large Sample } & \multirow{2}{*}{$\begin{array}{c}\text { Fuel mass, } \\
\mathrm{g}\end{array}$} & \multirow{2}{*}{$\begin{array}{c}\text { Estimated } \\
\text { burn-time, } \\
\mathrm{s}\end{array}$} & \multirow{2}{*}{$\begin{array}{c}\mathrm{T}_{\mathrm{o}} \\
\mathrm{K}\end{array}$} & \multirow{2}{*}{$\begin{array}{l}\mathrm{P}_{\mathrm{o}}, \\
\mathrm{hPa}\end{array}$} & \multirow{2}{*}{$\begin{array}{c}\text { Conductive } \\
\text { loss area, } \\
\mathrm{cm} \text { by } \mathrm{cm}\end{array}$} & \multirow{2}{*}{$\begin{array}{c}\mathrm{T}_{\max }, \\
\mathrm{K}\end{array}$} & \multirow{2}{*}{$\begin{array}{c}\mathrm{P}_{\max }, \\
\mathrm{hPa}\end{array}$} & \multirow{2}{*}{$\begin{array}{c}\text { Average } \\
\text { rate of } \\
\text { pressure } \\
\text { rise } \\
\mathrm{hPa} / \mathrm{s}\end{array}$} \\
\hline & $\begin{array}{l}\text { Width, } \\
\mathrm{cm}\end{array}$ & $\begin{array}{c}\text { Length, } \\
\mathrm{cm}\end{array}$ & & & & & & & & \\
\hline 1 & 50 & 100 & 45.0 & 105 & 294 & 1023 & $\mathrm{~N} / \mathrm{A}$ & 309 & 1075 & 0.50 \\
\hline 2 & 50 & 100 & 45.0 & 105 & 294 & 1023 & 50 by 20 & 299 & 1039 & 0.15 \\
\hline 3 & 50 & 100 & 45.0 & 105 & 294 & 950 & N/A & 309 & 997 & 0.45 \\
\hline 4 & 25 & 50 & 11.3 & 53 & 294 & 1023 & N/A & 300 & 1041 & 0.34 \\
\hline
\end{tabular}

For Condition 1, it is assumed that there are no conductive heat losses and the predicted peak pressure exceeds the ATV maximum limit of $1048 \mathrm{hPa}$. The other conditions show that various mitigation approaches can be employed to keep the maximum pressure at an acceptable level. Condition 2 assumes some level of conductive heat loss to the vehicle contents, such as to the experimental hardware (e.g., fuel sample holder, filters, etc.), and demonstrates that such a heat loss management scheme can be devised to prevent excessive pressure rise. For Conditions 3 and 4, no additional heat loss is assumed except to the external ATV walls. Condition 3 points out the obvious benefit of reducing the pressure prior to initiating the experiment without adversely affecting the fundamental flame behavior. Condition 4 assumes a scenario where the fuel sample is one-quarter of the original size (or mass) used for the baseline Fire Safety-1 experiment. Condition 4 depicts that reducing sample mass is another possible remedial approach to stay below the ATV contingency pressure, although it leads to pressure levels slightly above the ATV engineering limit of $1035 \mathrm{hPa}$ under the assumed conservative conditions. 
The following is the list of assumptions in current model predictions of transient pressure profiles in the ATV for the planned Fire Safety-1 experiment taking into consideration the conservative limiting conditions from References 5 to 7 :

- The ATV free volume is assumed to be $29.7 \mathrm{~m}^{3}$, i.e., smallest possible.

- The initial temperature is $21^{\circ} \mathrm{C}$.

- The initial pressure is $1023 \mathrm{hPa}$, except for Condition 3 where an operational scenario of reducing the initial pressure prior to $950 \mathrm{hPa}$ is explored.

- Though the area densities of candidate fuel sample materials are larger than that of Kimwipes by at least a factor of two, their burning rates are conservatively estimated from microgravity spread rate correlations developed for Kimwipes (Ref. 3); i.e., with the fastest spread rate possible. The burn-times reported in the table are obtained from spread rates assuming $15 \mathrm{~cm} / \mathrm{s} \mathrm{concurrent} \mathrm{flow}$ and 21 percent $\mathrm{O}_{2}$ at $1 \mathrm{~atm}$.

- The fuel mass is calculated by assuming a fuel area density equal to that of the in-house developed candidate fuel $\left(18.05 \pm 0.02 \mathrm{mg} / \mathrm{cm}^{2}\right.$ with a thickness of $0.31 \pm 0.02 \mathrm{~mm}$, composed of 50 percent cotton and 50 percent fiberglass by mass). The area densities of current candidate fuel materials are smaller than that of this in-house developed fuel, and hence, the tabulated fuel masses are conservative. The baseline large sample size for the Fire Safety- 1 experiment is 50 - by $100-\mathrm{cm}$.

- The current transient model accounts for the heat release from the fuel sample and heat loss from the gas to the vehicle walls by convection and radiation. Convective and near-field radiative losses to the experiment hardware and ATV internal structure have not been considered explicitly but have been accounted for by conductive losses to the sample holders. Once the variation of temperature with respect to time is determined, the pressure is calculated from the instantaneous temperature using the ideal gas relationship for constant volume.

- The total energy release is estimated by using Huggett's heat release factor ${ }^{2}$ of $13,100 \mathrm{~kJ} / \mathrm{kg}-\mathrm{O}_{2}$, typical for a hydrocarbon fuel like $\mathrm{C}_{6} \mathrm{H}_{10} \mathrm{O}_{5}$. The corresponding fire power is assumed to apply at a constant rate throughout the given burn-time; i.e., a constant burning rate with instantaneous ignition and flame-out.

For all conditions, the maximum pressure is reached at the end of the combustion event (shown as the estimated burn-time in Table III). At this point, the rate of pressure rise is found to be at its minimum. A typical model prediction of pressure and temperature profile is shown in Figure 7 for Condition 2 . The average values for the rate of pressure rise $\mathrm{dP} / \mathrm{dt}$ and temperature rise $\mathrm{dT} / \mathrm{dt}$ are obtained by simply dividing the difference between their corresponding maximum and initial values by the burn-time. Therefore, these average rates reported in the table are conservative for evaluating the volume expansion rates and associated mass release rates by the relief valve.

Current estimates, while preliminary and obtained from conservative analyses, show that the Fire Safety-1 experiment is feasible within ATV pressure limits. More refined and validated models will guide the future efforts. Tests are planned to obtain direct measurements of pressure rise in a large sealed volume (VF-13) to validate the model predictions. In these experiments, we will investigate the effect of sequentially burning the small and large samples on the peak pressure rise as well as quantifying the heat loss mechanisms that play a significant role in the energy balance. The contingency plan is to reduce the initial pressure of the ATV while attempting to mitigate the risk in the uncertainty in the initial pressure through sample selection and sample size reduction. These efforts at NASA Glenn will be augmented by our collaboration with the ESA science team. 


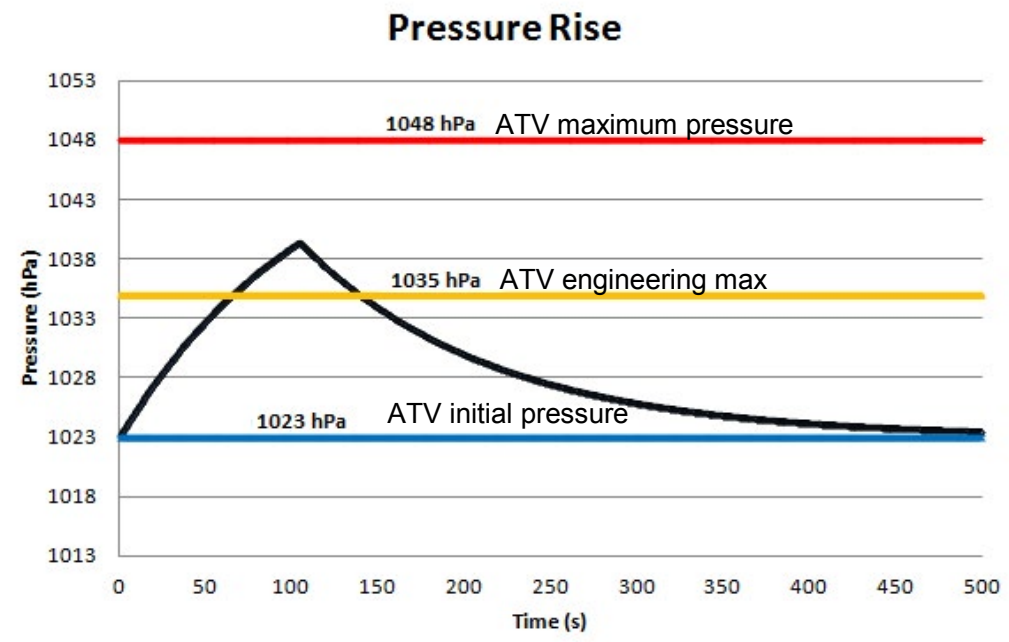

Temperature Rise

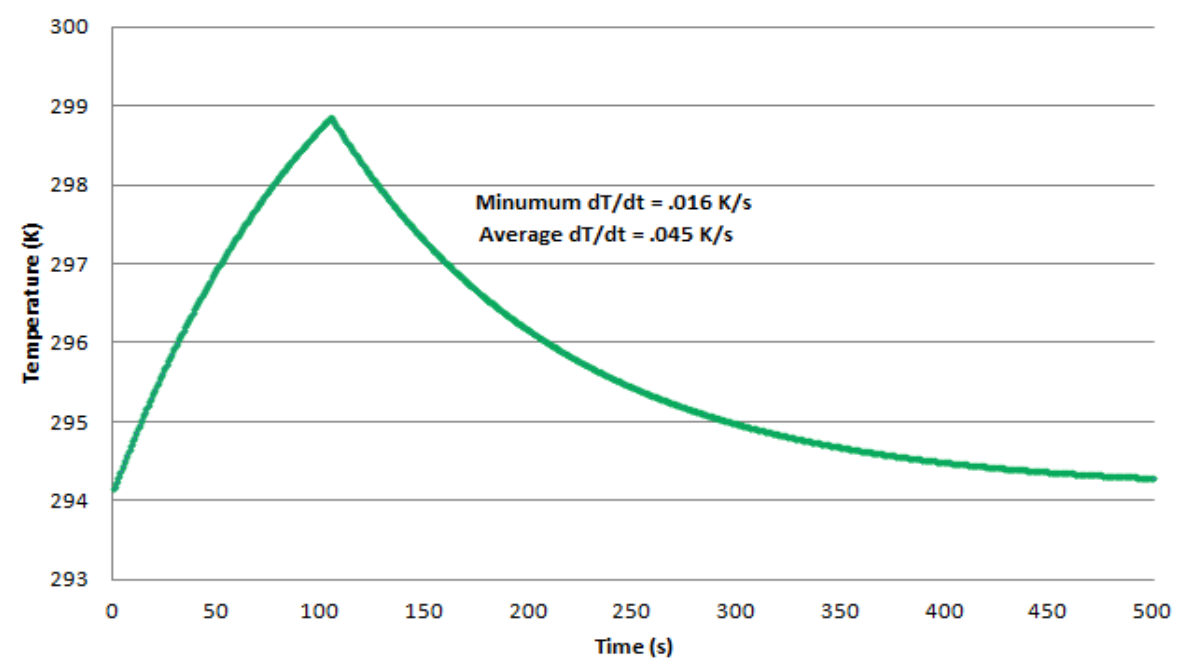

Figure 7.-Predicted pressure and temperature profiles in ATV for Fire Safety-1 experiment, Condition 2 in Table III.

\section{Summary and Conclusions}

A lumped-parameter transient model is described which accounts for the energy gain due to the burning and its associated heat release of a typical thin fuel material in a sealed enclosure and the energy losses due to heat transfer by radiation from the flame to the walls, by convection from the heated gases to the enclosure, and by conduction from the flame to the fuel-sample holder. The temperature and associated pressure profiles during and after the combustion event are predicted. The model is first calibrated against an experimentally measured pressure profile obtained from burning one type of fuel in a closed chamber. It is then used to predict pressure profiles obtained from burning a different type and various quantities of fuel material. The calibrated model predictions are found to be quite reasonable both in terms of the full pressure profile and determining the maximum pressure for fuel energy contents varied by a factor of seven.

A sensitivity analysis is performed for the predictions of maximum pressure with respect to uncertainties in parameter values employed by the model. It is determined that the model sensitivity is highest to the initial pressure, followed by average fire power, total internal gas volume of the enclosure, 
and burn-time. Among the heat loss parameters, the sensitivity is greatest to the available internal surface area and to the flame temperature. Therefore, for a given energy input and heat release rate, the maximization of total internal surface area available for convective heat transfer and accurate determination of the flame temperature are key variables for a more reliable prevention of overpressurization in the enclosure.

Albeit its limited capabilities and validation, the current model is used as a practical tool to guide us in the design of the Fire Safety-1 experiment proposed to be conducted on an orbiting vehicle such as the ATV. The first-cut model predictions of the transient pressure profiles and maximum pressures attainable in the ATV show that the Fire Safety-1 experiment is feasible within the ATV vehicle constraints. Various scenarios and mitigation approaches are suggested to prevent over-pressurization. The development of more refined models and their validation by tests in larger sealed chambers are currently underway for the safe conduct of the experiment in any potential orbiting vehicle.

\section{References}

1. Ross, H. D. (ed.), Microgravity combustion: fire in free fall, San Diego, CA, Academic Press (2001).

2. Huggett, C., Estimation of Rate of Heat Release by Means of Oxygen Consumption Measurements, Fire Mater. Vol. 4, 61-65 (1980).

3. Olson, S.L., Ruff, G.A., and Miller, F.J. "Microgravity Flame Spread in Exploration Atmospheres: Pressure, Oxygen, and velocity Effects on Opposed and Concurrent Flame Spread," SAE Paper No. 2008-01-2055, $38^{\text {th }}$ International Conference on Environmental Systems, San Francisco, CA, June 29July 2, 2008.

4. Abu-Romia and T'ien, "Appropriate mean absorption coefficients for infrared radiation of gases," ASME Journal of Heat Transfer, 89C:321-327 (1967).

5. ATV Cargo Accommodation Handbook, 20 November 2004, ATV-HB-AI-0001-7, ATV-ALS-UM0001.

6. ATV ICC User Manual ATV-ALS-UM-0002, Issue 06, February 28, 2005.

7. ATV Dry Cargo Integration Interface Definition Document, Issue 03 Rev1, 18 Jan. 2010, OPS-IDD$0-200$. 



\begin{tabular}{|c|c|c|}
\hline \multicolumn{2}{|c|}{ REPORT DOCUMENTATION PAGE } & $\begin{array}{l}\text { Form Approved } \\
\text { OMB No. 0704-0188 }\end{array}$ \\
\hline \multicolumn{3}{|c|}{ 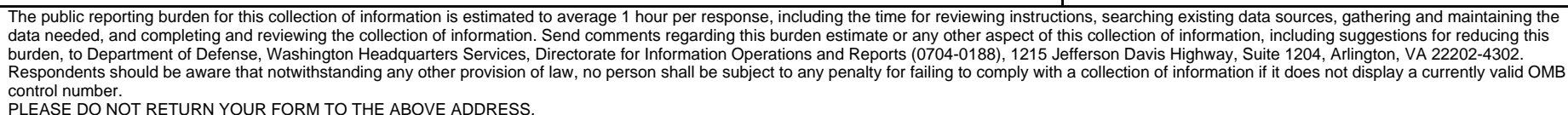 } \\
\hline $\begin{array}{l}\text { 1. REPORT DATE (DD-MM-YYYY) } \\
01-09-2012\end{array}$ & $\begin{array}{l}\text { 2. REPORT TYPE } \\
\text { Technical Memorandum }\end{array}$ & 3. DATES COVERED (From - To) \\
\hline \multirow{3}{*}{\multicolumn{2}{|c|}{$\begin{array}{l}\text { 4. TITLE AND SUBTITLE } \\
\text { Prevention of Over-Pressurization During Combustion in a Sealed Chamber }\end{array}$}} & 5a. CONTRACT NUMBER \\
\hline & & 5b. GRANT NUMBER \\
\hline & & 5c. PROGRAM ELEMENT NUMBER \\
\hline \multirow{3}{*}{\multicolumn{2}{|c|}{$\begin{array}{l}\text { 6. AUTHOR(S) } \\
\text { Gokoglu, Suleyman, A.; Niehaus, Justin, E.; Olson, Sandra, L.; Dietrich, Daniel, L.; Ruff, } \\
\text { Gary, A.; Ferkul, Paul, V.; Johnston, Michael, C. }\end{array}$}} & 5d. PROJECT NUMBER \\
\hline & & 5e. TASK NUMBER \\
\hline & & $\begin{array}{l}\text { 5f. WORK UNIT NUMBER } \\
\text { WBS 067463.04.05.04.03 }\end{array}$ \\
\hline \multicolumn{2}{|c|}{$\begin{array}{l}\text { 7. PERFORMING ORGANIZATION NAME(S) AND ADDRESS(ES) } \\
\text { National Aeronautics and Space Administration } \\
\text { John H. Glenn Research Center at Lewis Field } \\
\text { Cleveland, Ohio 44135-3191 }\end{array}$} & $\begin{array}{l}\text { 8. PERFORMING ORGANIZATION } \\
\text { REPORT NUMBER } \\
\text { E-18417 }\end{array}$ \\
\hline \multirow{2}{*}{\multicolumn{2}{|c|}{$\begin{array}{l}\text { 9. SPONSORING/MONITORING AGENCY NAME(S) AND ADDRESS(ES) } \\
\text { National Aeronautics and Space Administration } \\
\text { Washington, DC 20546-0001 }\end{array}$}} & $\begin{array}{l}\text { 10. SPONSORING/MONITOR'S } \\
\text { ACRONYM(S) } \\
\text { NASA }\end{array}$ \\
\hline & & $\begin{array}{l}\text { 11. SPONSORING/MONITORING } \\
\text { REPORT NUMBER } \\
\text { NASA/TM-2012-217712 }\end{array}$ \\
\hline
\end{tabular}

\section{DISTRIBUTION/AVAILABILITY STATEMENT}

Unclassified-Unlimited

Subject Category: 31

Available electronically at http://www.sti.nasa.gov

This publication is available from the NASA Center for AeroSpace Information, 443-757-5802

\section{SUPPLEMENTARY NOTES}

\section{ABSTRACT}

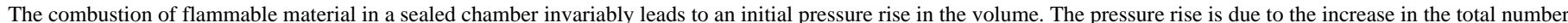

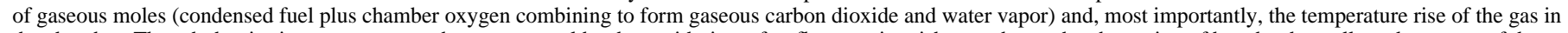
the chamber. Though the rise in temperature and pressure would reduce with time after flame extinguishment due to the absorption of heat by the walls and contents of the sealed spacecraft, the initial pressure rise from a fire, if large enough, could lead to a vehicle over-pressure and the release of gas through the pressure relief valve. This paper presents a simple lumped-parameter model of the pressure rise in a sealed chamber resulting from the heat release during combustion. The transient model considers the

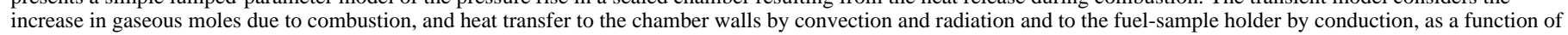
the burning rate of the material. The results of the model are compared to the pressure rise in an experimental chamber during flame spread tests as well as to the pressure fall-

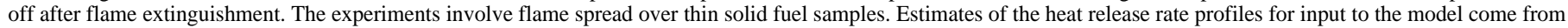
the assumed stoichiometric burning of the fuel along with the observed flame spread behavior. The sensitivity of the model to predict maximum chamber pressure is determined with respect to the uncertainties in input parameters. Model predictions are also presented for the pressure profile anticipated in the Fire Safety-1 experiment, a material flammability and fire safety experiment proposed for the European Space Agency (ESA) Automated Transfer Vehicle (ATV). Computations are done for a range of scenarios including various initial pressures and sample sizes. Based on these results, various mitigation approaches are suggested to prevent vehicle over-pressurization and help guide the definition of the space experiment.

\section{SUBJECT TERMS}

Combustion; Fire; Fire prevention; Fire safety; Combustion chamber

\begin{tabular}{|c|c|c|c|}
\hline \multicolumn{3}{|c|}{ 16. SECURITY CLASSIFICATION OF: } & \multirow{2}{*}{$\begin{array}{l}\text { 17. LIMITATION OF } \\
\text { ABSTRACT } \\
\text { UU }\end{array}$} \\
\hline $\begin{array}{l}\text { a. REPORT } \\
U\end{array}$ & $\begin{array}{l}\text { b. ABSTRACT } \\
\mathrm{U}\end{array}$ & $\begin{array}{l}\text { c. THIS } \\
\text { PAGE } \\
\text { U }\end{array}$ & \\
\hline
\end{tabular}

18. NUMBER
OF
PAGES
22

19a. NAME OF RESPONSIBLE PERSON STI Help Desk (email:help@sti.nasa.gov) 19b. TELEPHONE NUMBER (include area code) 443-757-5802 

